\title{
EVALUATION OF SEA SURFACE TEMPERATURE FROM HY-2 SCANNING MICROWAVE RADIOMETER
}

\author{
Mingkun Liu and Lei Guan \\ Department of Marine Technology \\ College of Information Science and Engineering \\ Ocean University of China, Qingdao, China
}

Introduction The accurate observations of sea surface temperature (SST) from satellite microwave radiometers have been available since the launch of TRMM. The TRMM Microwave Imager (TMI) SST has an error of about $0.6^{\circ} \mathrm{C}$. Following TMI, SST products have been derived from the microwave radiometers such as AMSR-E onboard Aqua, WindSat onboard Coriolis and AMSR2 onboard GCOM-W. The HY-2 satellite was launched in August 2011 which carries four instruments including a Scanning Microwave Radiometer (HY-2 RM). The microwave radiometer has low frequency channels at $6.6 \mathrm{GHz}$ and $10.7 \mathrm{GHz}$ which are capable of measuring SST from space. The preliminary assessment of the HY-2 RM SST products with NCEP re-analysis data from 10 October to October 202011 showed an rms error of about $2{ }^{\circ} \mathrm{C}$. The evaluation of the products with NDBC and Argo SST measurements in the first half year of 2012 showed the accuracy of the initial SST products is about $-0.49 \pm 1.63^{\circ} \mathrm{C}$ and $-0.28 \pm 1.68^{\circ} \mathrm{C}$ respectively. And the comparison of the HY-2 RM SST with WindSat SST data in the same period indicated an error of $1.8^{\circ} \mathrm{C}$. In this study, the HY-2 RM L2A SST products during the period of January 2012 to December 2014 are evaluated with WindSat and buoy SST data. The relationships between SST difference and the sea surface parameters such as wind speed and SST are investigated.

Comparison of HY-2 RM SST with buoy and WindSat SST data The HY-2 RM L2A SST products have been developed and distributed by the National Satellite Ocean Application Service (NSOAS) of the State Oceanic Administration (SOA). The L2A SST products were projected to daily ascending and descending equal-angle maps with a grid size of 0.25 degree. Fig. 1 shows daily projected HY-2 RM SST on 14 February, 2013.
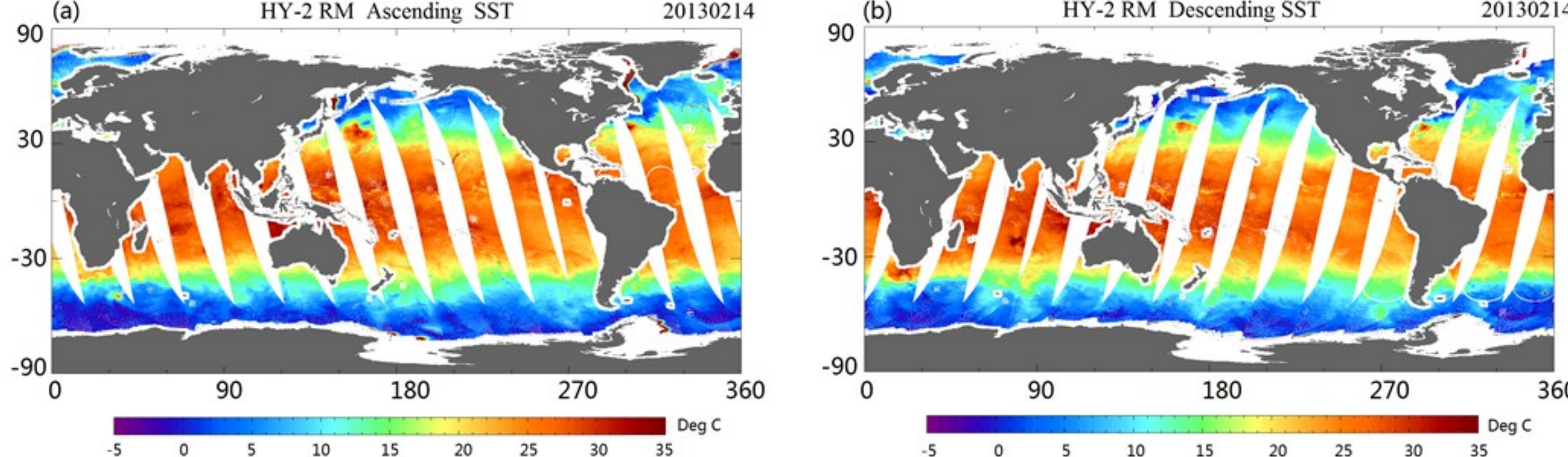

Fig.1. HY-2 RM SST on 14 February 2013 (a. Ascending b. Descending)

The collocations of HY-2 RM, Windsat, and buoy SST data are generated with the spatial window of $0.25^{\circ}$ and the temporal window of 0.5 hour. Fig. 2 shows daily SST difference and three year SST difference of HY-2 RM minus buoy (Fig. 2a and 2d), HY-2 RM minus Windsat (Fig. $2 \mathrm{~b}$ and $2 \mathrm{e}$ ), and Windsat minus buoy (Fig. $2 \mathrm{c}$ and $2 \mathrm{f}$ ). The overall three year statistics of $\mathrm{HY}-2 \mathrm{RM}$ with buoy and Windsat indicate cold biases of $-0.45^{\circ} \mathrm{C}$ and $-0.41^{\circ} \mathrm{C}$ and relatively large standard deviations of $1.73^{\circ} \mathrm{C}$ and $1.72^{\circ} \mathrm{C}$. The comparison of Windsat with buoy shows the bias of $-0.03^{\circ} \mathrm{C}$ and standard deviation of $0.53^{\circ} \mathrm{C}$.
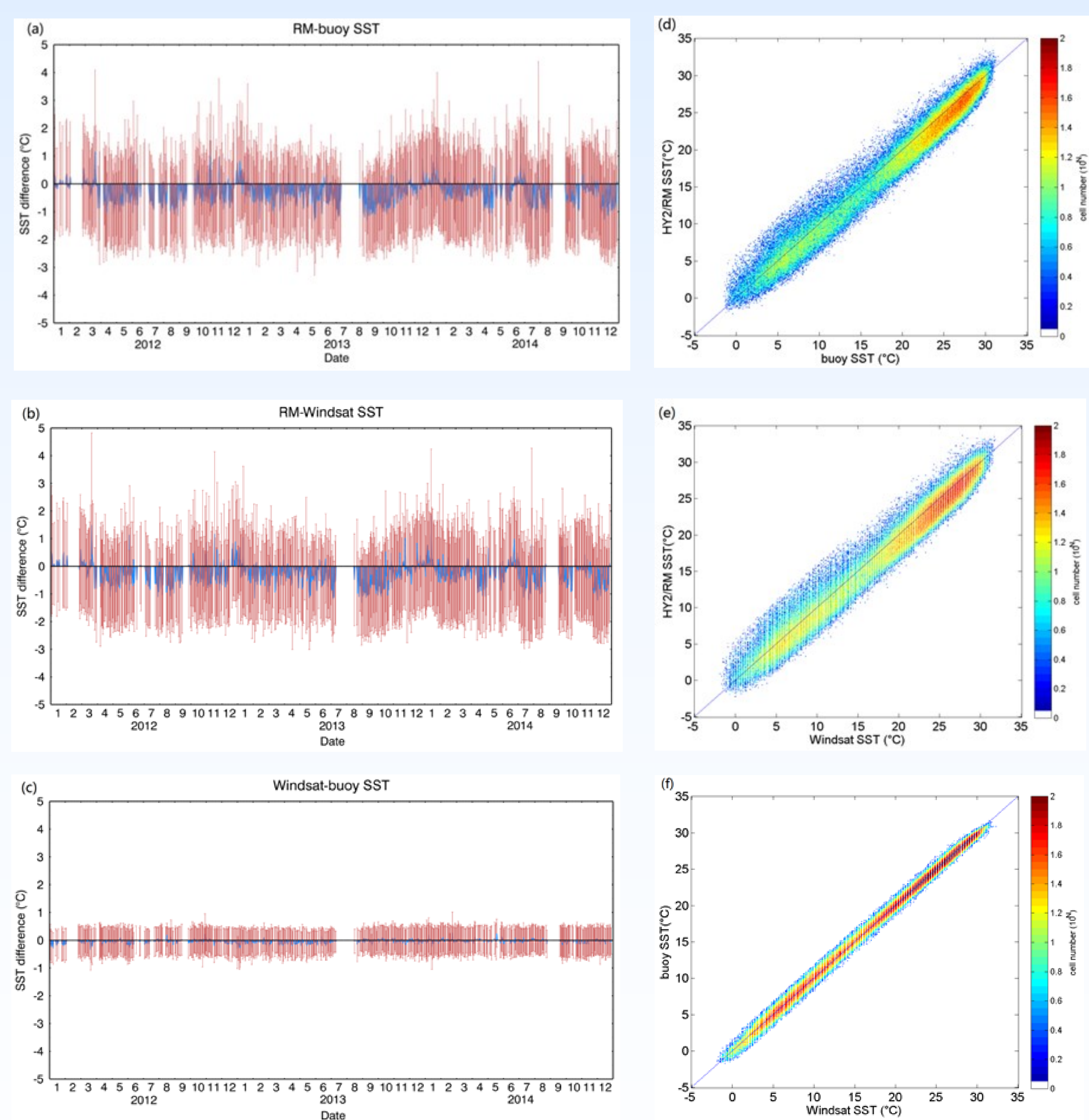

Fig. 2. Daily statistics (left panel) and three year statistics (right panel) of the SST difference between (a and d) HY-2 RM and buoy, (b and e) HY-2 RM and Windsat, (c and f) Windsat and buoy SST data
To understand the variation of the daily collocations, latitude-time distribution of the daily mean difference of HY-2 RM minus buoy SST averaged into $1^{\circ}$ from January 2012 to December 2014 is shown in Fig. 3. Fig. 4 is the latitude-time diagram of the Windsat daily surface wind speed from January 2012 to December 2014. In the mid and high latitude ocean of the northern hemisphere, it is obvious that the HY-2 RM SSTs are higher than buoy SSTs and the difference is larger than $3^{\circ} \mathrm{C}$ during the period from November to March of the following year. In the southern ocean where strong westerly winds prevail, HY-2 RM SSTs are also higher than buoy SSTs during the period from April to October. The warmer bias regions are coincident with wind speeds higher than $8 \mathrm{~m} / \mathrm{s}$. The SST difference between $\mathrm{HY}-2 \mathrm{RM}$ and buoy data is within $1^{\circ} \mathrm{C}$ in the near-equatorial and low latitude ocean where the wind speeds are low.

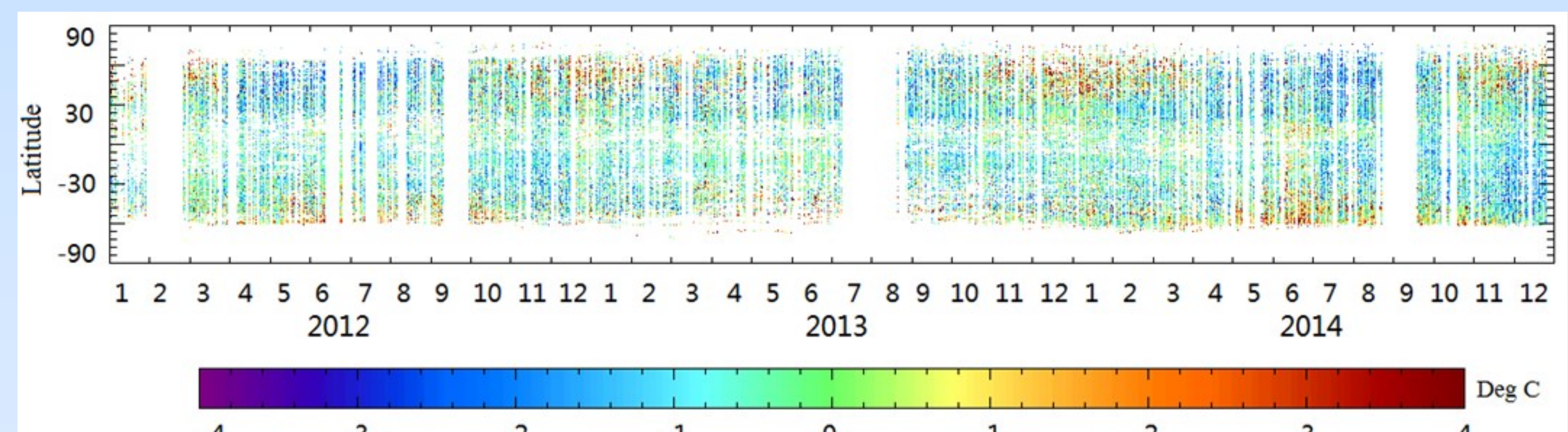

Fig. 3. Latitude-time diagrams of the SST difference between HY-2 RM and buoy data

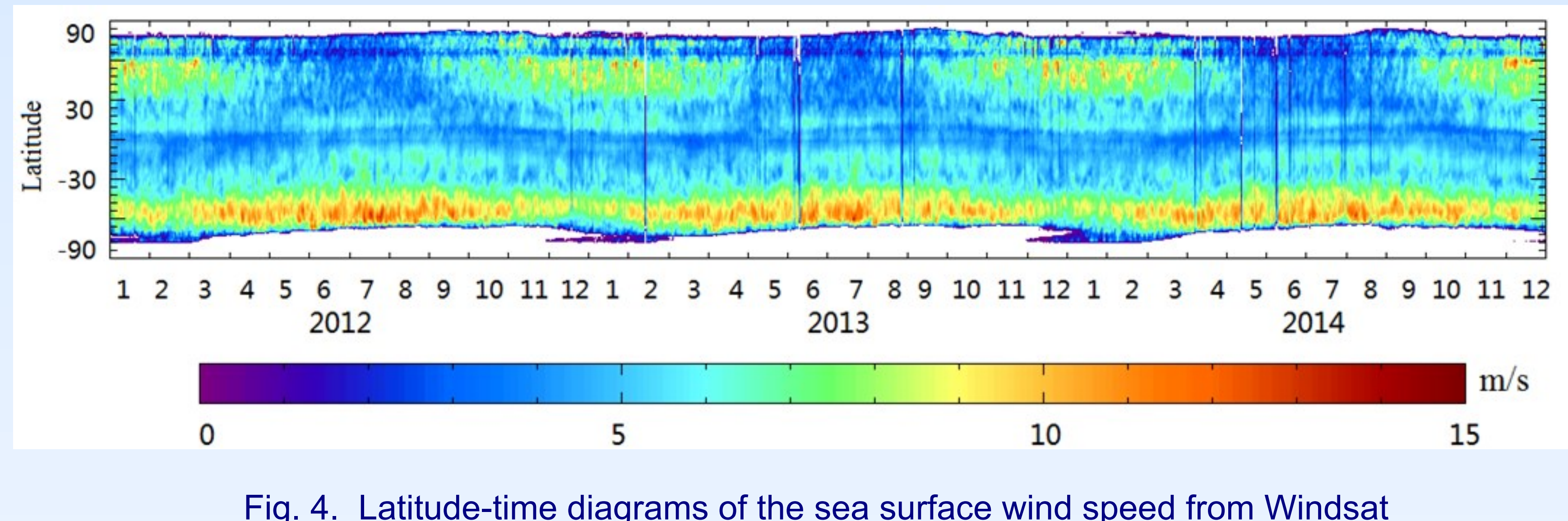

Discussion The SST difference was investigated using the matchups of HY-2 RM and buoy data. Fig.5 is the variation of the difference against wind speed and SST. The results show negative bias below $10 \mathrm{~m} / \mathrm{s}$ and positive bias above $10 \mathrm{~m} / \mathrm{s}$. The smallest standard deviation appears when wind speed is around $6 \mathrm{~m} / \mathrm{s}$ and the bias and standard deviation increase with the increasing wind speed, which is consistent with the results shown in Fig. 3 and Fig.4. Fig. 5 shows larger bias and standard deviation when SST is lower. The bias decreases when SST increases, from $2^{\circ} \mathrm{C}$ in the cold waters to about $-0.5^{\circ} \mathrm{C}$ under most of the SST values. The standard deviations are around $2^{\circ} \mathrm{C}$ and decrease to smaller value in warmer waters. The SST error sources will be further investigated.
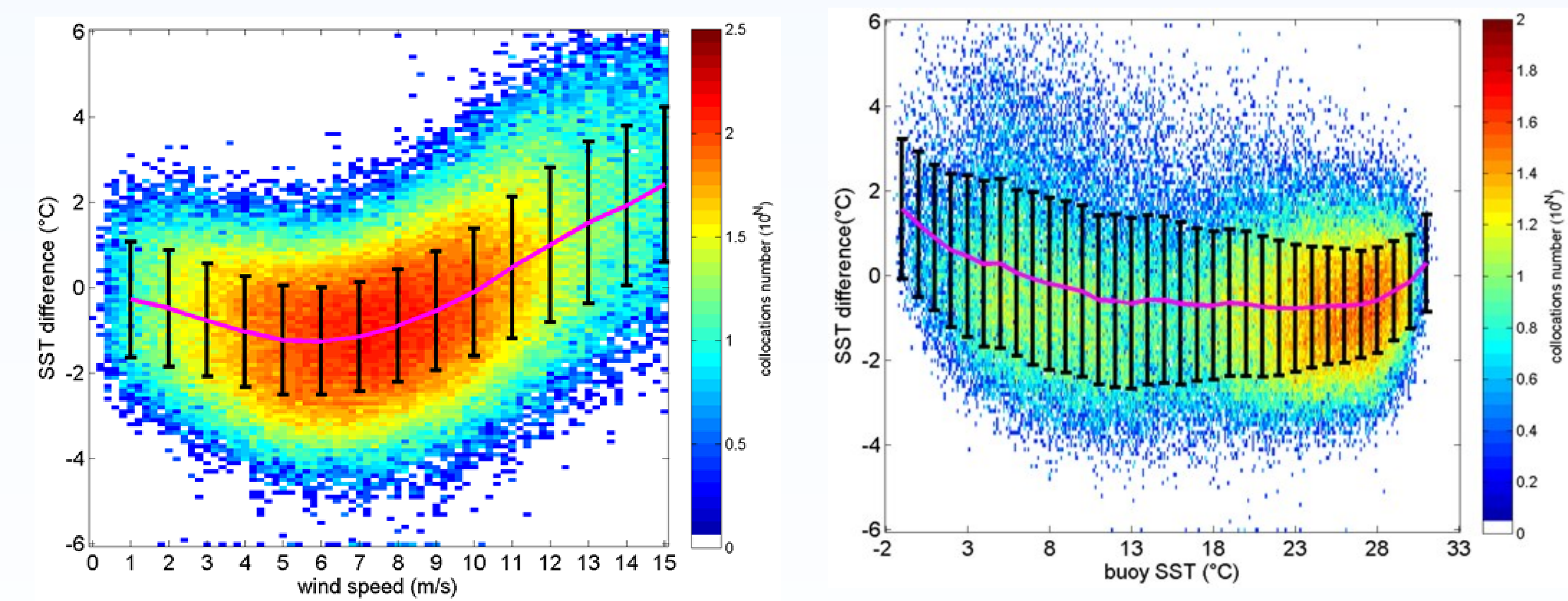

Fig.5. Variations of the SST difference with wind speed and SST 